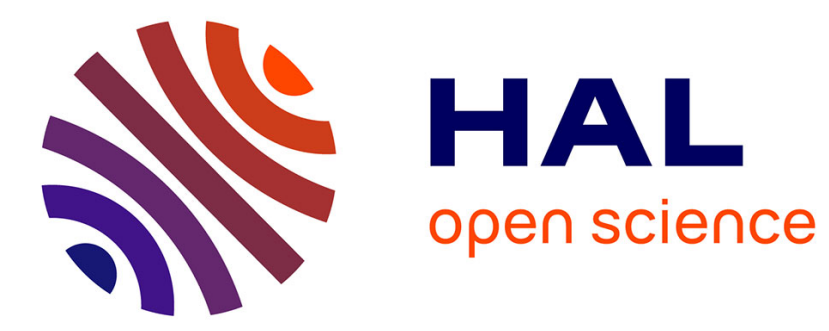

\title{
Decrease in rice aroma after application of growth regulators
}

\author{
Goufo, Wongpornchai, Tang
}

\section{To cite this version:}

Goufo, Wongpornchai, Tang. Decrease in rice aroma after application of growth regulators. Agronomy for Sustainable Development, 2011, 31 (2), pp.349-359. 10.1051/agro/2010011 . hal-00930452

\section{HAL Id: hal-00930452 https://hal.science/hal-00930452}

Submitted on 1 Jan 2011

HAL is a multi-disciplinary open access archive for the deposit and dissemination of scientific research documents, whether they are published or not. The documents may come from teaching and research institutions in France or abroad, or from public or private research centers.
L'archive ouverte pluridisciplinaire HAL, est destinée au dépôt et à la diffusion de documents scientifiques de niveau recherche, publiés ou non, émanant des établissements d'enseignement et de recherche français ou étrangers, des laboratoires publics ou privés. 


\title{
Research article
}

\section{Decrease in rice aroma after application of growth regulators}

\author{
Piebiep GOUFO ${ }^{1,2}$, Sugunya WONGPORNCHAI ${ }^{3}$, Xiangru TANG ${ }^{1, *}$ \\ ${ }^{1}$ Department of Crop Science and Technology, South China Agricultural University, Guangzhou 510642, P.R. China \\ ${ }^{2}$ Department of Biochemistry, University of Yaoundé I, Yaoundé FS 812, Cameroon \\ ${ }^{3}$ Department of Chemistry, Chiang Mai University, Chiang Mai 50200, Thailand
}

(Accepted 8 February 2010) (Published online: 19 May 2010)

\begin{abstract}
Aromatic rices (Oryza sativa L.) compared to the leading varieties are low-yielding, susceptible to lodging and prone to attack by a number of insect pests and diseases. Under these conditions, various agricultural chemicals such as fertilizers, pesticides and growth regulators have been used for their cultivation. Few investigations, however, have examined the influence of these chemicals on rice aroma and flavor. In this study, changes in rice aroma after treatment with gibberellic acid, paclobutrazol, 3-indole acetic acid, and a regulator mixture consisting of paclobutrazol, proline and zinc chloride were for the first time examined using two aromatic rice cultivars. Applications were carried out after $25 \%$ of panicles had emerged. We studied 12 odor-active compounds, extracted and identified using static headspace coupled with gas chromatography. At the concentrations tested, all treatments with growth regulators resulted in reduced aroma content that affected overall flavor. In a smelling evaluation, control samples were significantly higher in intensity than treated samples. The difference between the aromas of control and treated samples was largely related to 2-acetyl-1-pyrroline, the major rice aroma compound, and lipid oxidation volatiles. For instance, in the cultivar Guixiangzhan grown during the late season, gibberellic acid treatment decreased the content of 2-acetyl-1-pyrroline by $19 \%$, 3-indole acetic acid by $9 \%$, paclobutrazol by $22 \%$, and the regulator mixture by $21 \%$ compared with the control. Similar trends were observed in the Peizaruanxiang cultivar, with decreases ranging from 10 to $24 \%$. Our findings demonstrate that treatments with growth regulators inhibited the metabolic processes associated with the formation of volatile compounds.
\end{abstract}

aromatic rice / paclobutrazol / gibberellic acid / 3-indole acetic acid / 2-acetyl-1-pyrroline / lipid-derived volatiles

\section{INTRODUCTION}

Aromatic rices constitute a special subgroup of rice that is becoming increasingly popular all over the world. They are a bit more expensive, but their qualities are well worth the price. The economic value of aromatic rice depends mainly on the flavor of the grains. Studies involving the isolation and identification of odor-active compounds in rice grains have been performed for decades. The literature, however, reveals that other than lipid oxidation products and 2-acetyl-1-pyrroline, there are few specific volatile compounds or classes of compounds that contribute to other desirable or undesirable aroma or flavor attributes in rice (Buttery et al., 1988; Petrov et al., 1996; Widjaja et al., 1996; Champagne, 2008; Maraval et al., 2008; Yang et al., 2008).

Small variations in flavor can make rice highly desired by or unacceptable to targeted consumers. Rice aroma and flavor are determined by genetic factors, but are also very much dependent on environmental conditions during production, and

*Corresponding author: tangxr@scau.edu.cn pre- and post-harvest practices. The environmental and genetic regulation of rice aroma has been reviewed by Bourgis et al. (2008), Bradbury et al. (2008b) and Champagne (2008). Agricultural chemicals are extensively used in growing aromatic rices. This is mainly because aromatic rices are low-yielding and susceptible to lodging (Yoshihashi et al., 2002; Bradbury et al., 2008b). Few studies have explored the impact of agricultural chemicals on the flavor of rice. It was reported in a pioneering study that rice plants fertilized at a normal nitrogen rate of $150 \mathrm{~kg} \mathrm{~N} / \mathrm{ha}$ had a lower concentration of volatile compounds compared with plants fertilized at a lower nitrogen rate (Bradbury et al., 2008b).

In crop production, application of growth regulators has been used extensively for a variety of purposes, which include improved growth and yield, and survival under different stress conditions (Yim et al., 1997; Loutfi and Chlyah, 1998; Sawan and Sakr, 1998; Sudria et al., 2001; Mander, 2003; Lancon et al., 2007). Despite extensive literature on the subject, however, there are no reports of attempts made to evaluate the effects of the application of growth hormones on the aroma quality of rice grains. Hence, in the present study, the possible effect of 
growth regulators applied as foliar spray on the volatile components of rice was determined using two aromatic rice cultivars grown in South China. The influence of the different treatments on odor-active compounds in brown and white rice grains was analyzed using static headspace coupled with gas chromatography. In addition, yield, milling quality, grain vitreosity, amylose and protein contents of the two aromatic rice cultivars as influenced by treatments with growth regulators were investigated.

\section{MATERIALS AND METHODS}

\subsection{Growth regulators and standard compounds}

Gibberellic acid 90\%, paclobutrazol 95\%, 3-indole acetic acid $99 \%$, proline and zinc chloride were purchased from Xiamen Topusing Chemical Co., Ltd. (Fujian, P.R. China).

Authentic compounds used for identification were $(E)$ 2-hexenal, hexanal, 1-nonanol, decanal and benzaldehyde (Sigma, St. Louis, MO), octanal, 1-pentanol and 1-hexanol (Fluka, Buchs, Switzerland), 2,6-dimethylpyridine used as an internal standard, 1-heptanol (BDH Chemicals, Poole, England), 1-octanol, and nonanal (Merck, Darmstadt, Germany). 2-acetyl-1-pyrroline was synthesized from 2-acetylpyrole, 5\% rhodium on an activated alumina catalyst, celite (Fluka, Buchs, Switzerland), silver carbonate (Aldrich, Milwaukee, WI), benzene and methanol (Merck, Darmstadt, Germany), as described previously (Wongpornchai et al., 2004; Sriseadka et al., 2006). The purity of the synthesized 2-acetyl-1pyrroline compound was confirmed by gas chromatographymass spectrometry, infrared, and ${ }^{1} \mathrm{H}$ and ${ }^{13} \mathrm{C}$-nuclear magnetic resonance, and the actual concentration determined using tetramethylsilane (Aldrich, Steinheim, Germany) as an internal standard. Standard stock solutions were prepared with benzyl alcohol (Fisher, Loughborough, UK) and stored at $-80{ }^{\circ} \mathrm{C}$ until used. Reagents used for quality evaluation were all procured from Guanghua Chemicals (Guangzhou, P.R. China). Water was purified through an Aquapro AWL-6001-P distillator (EverYoung, Guangzhou, P.R. China).

\subsection{Rice samples and growth conditions}

Experiments to determine the aroma and quality response of two aromatic rice cultivars, namely Guixiangzhan and Peizaruanxiang, to different growth regulators were conducted during the early and late seasons of 2008, at the South China Agricultural University's experimental farm in Guangzhou, P.R. China, on a sandy loam soil. The two cultivars accounted for the major aromatic rice cultivars grown in the region (Goufo et al., 2010). Seeds of Guixiangzhan were collected from a previous harvest, while those of Peizaruanxiang were purchased from a local shop situated inside the University. Transplanting was done manually in early April for the early season and late July for the late season, with hill spacing of $20 \mathrm{~cm} \times 20 \mathrm{~cm}$. Paddy fields were treated like all conventional cultivars with a common fertilizer and pesticide program.

\subsection{Foliar application of growth regulators}

Foliar application of growth regulators was carried out after the emergence of approximately $25 \%$ of panicles by spraying plants uniformly to the point of run-off (approximately $100 \mathrm{~mL} / \mathrm{m}^{2}$ ) using a Gloria type hand sprinkler (Guangzhou, P.R. China) with constant flow. The experimental design for all experiments was a randomized complete block with three replications, each consisting of a $16.20-\mathrm{m}^{2}$ plot size. Treatments included (1) a plot sprayed with distilled water and maintained as control, (2) a plot sprayed with $40 \mathrm{mg} / \mathrm{L}$ gibberellic acid prepared using $95 \%$ ethanol as surfactant, (3) a plot sprayed with $25 \mathrm{mg} / \mathrm{L}$ paclobutrazol, (4) a plot sprayed with $25 \mathrm{mg} / \mathrm{L} 3$-indole acetic acid, and (5) a plot sprayed with a combination of paclobutrazol $(15 \mathrm{mg} / \mathrm{L})$, proline $(120 \mathrm{mg} / \mathrm{L})$ and zinc chloride $(2000 \mathrm{mg} / \mathrm{L})$, which we will refer to as regulator mixture. The treatments were applied late in the afternoon. The concentration of each substance was selected on the basis of previous experiments conducted since 2003 by our laboratory to establish optimum dosages for various rice cultivars, including the two aromatic cultivars used in this study, and on actual practices employed by farmers in Guangzhou. Gibberellic acid was selected for improved paddy yield, 3-indole acetic acid for improved grain quality, and paclobutrazol for lodging prevention and increased efficiency of mechanical harvest. In one of those studies, combined application of paclobutrazol, proline and zinc chloride could remarkably reverse the effects of various environmental stresses such as salinity on rice, and therefore was included in the study.

\subsection{Harvesting, storage, yield and quality parameters measured}

At maturity when $95 \%$ of the grains turned yellow, a $2.6-\mathrm{m}^{2}$ area from the center three rows of each plot was harvested using a sickle. Yield components measured included average paddy yield and 1000-grain rough rice weight. The samples were threshed and dried to $120 \mathrm{~g} / \mathrm{kg}$ moisture content, then separated into two sets. The first set, used for the analysis of volatile compounds, was kept in a refrigerator at $8{ }^{\circ} \mathrm{C}$, while the second set was left at room temperature for three months and used to determine rice quality parameters. Head rice recovery was estimated using a Jing Mi testing rice grader, JFQS-1320 (Guangzhou, P.R. China), grain vitreosity using a SDE-A light box (Guangzhou, P.R. China), and amylose and protein content as described in the literature (Juliano and Villareal, 1993). Duplicate measurements were taken for each sample and the mean value of three samples per treatment was taken as the final result.

\subsection{Static headspace and semi-quantification of some major rice volatiles}

Brown rice samples were ground (Moulinex, Caen, France) into a powder (less than $0.3 \mathrm{~mm}$ in diameter) which was used immediately. Samples were aged approximately three months 
for the late harvest and six months for the early harvest. Extractions were performed in duplicate for each sample with three samples per treatment.

The headspace procedure and conditions were optimized to provide a wide linear range useful for extraction and identification of compounds of interest. Each sample $(3.0 \mathrm{~g})$ was weighed into a $20-\mathrm{mL}$ headspace vial. One $\mu \mathrm{L}$ of $2,6-$ dimethylpyridine as an internal standard $(0.5 \mathrm{mg} / \mathrm{mL})$ was added to the content of the vial before sealing it airtight with a polytetrafluoroethylene/silicone septum secured by an aluminum cap (Restek Corp., Bellefonte, PA). Sample vials were introduced into the headspace autosampler (Agilent Technologies G1888, Wilmington, DE) and equilibrated for $9 \mathrm{~min}$ at $120{ }^{\circ} \mathrm{C}$ with high-speed shaking prior to collection of the volatile components. After pressurizing, loop filling and loop equilibration times of $0.10,0.01$ and $0.60 \mathrm{~min}$, respectively, a sample of headspace was collected through a 3-mL sample loop and automatically transferred to the gas chromatography via a heated transfer line for $0.40 \mathrm{~min}$. The oven, sample loop and transfer line temperatures were set at 120, 130 and $140{ }^{\circ} \mathrm{C}$, respectively. Gas chromatographic separation was performed on an Agilent 6890N GC system (Agilent Technologies, Wilmington, DE) coupled to a flame ionization detector, and equipped with Agilent ChemStation software A.01.04 and B.01.03 for data collection and evaluation. Separation was performed using a $60 \mathrm{~m} \times 0.32 \mathrm{~mm}$ i.d. $\times 1.0 \mu \mathrm{m}$ film thickness HP-5 fused silica capillary column (J\&W Scientific, Folsom, $\mathrm{CA}$ ), with a splitless injection at $230{ }^{\circ} \mathrm{C}$. The temperature of the HP-5 column was programed starting at $50{ }^{\circ} \mathrm{C}$ after injection, after which it was increased at a rate of $5{ }^{\circ} \mathrm{C} / \mathrm{min}$ from 50 to $200{ }^{\circ} \mathrm{C}$. Gas chromatography/flame ionization detector experiments were carried out with the temperature of the detector set at $250{ }^{\circ} \mathrm{C}$ and a carrier gas flow rate of $3 \mathrm{~mL} / \mathrm{min}$.

Rice sample volatiles were identified by their gas chromatography retention times relative to those of authentic compounds run under the same conditions, and by comparison of the calculated retention indices with the literature data. Peak areas were obtained with the aid of the instrument's digital integrator and the concentrations were expressed as 2,6-dimethylpyridine (2,6-DMP) equivalents using the formula:

concentration $(\mathrm{ng} / \mathrm{g})=$ compound area

$\times \frac{2,6-\mathrm{DMP} \text { concentration }(\mathrm{ng} / \mu \mathrm{L}) \times \text { injection volume }(\mu \mathrm{L})}{2,6-\mathrm{DMP} \text { area } \times \text { rice sample weight }(\mathrm{g}) \times \text { recovery factor }}$.

The recovery factor of compounds of interest was determined, with most of the components showing satisfactory recoveries.

\subsection{Quantification of 2-acetyl-1-pyrroline}

The procedure to extract 2-acetyl-1-pyrroline from the rice samples was the same as described above with some minor changes. Instead of the flame ionization detector, a nitrogen-phosphorus detector was used as reported previously
(Sriseadka et al., 2006). Two replications of $1.0 \mathrm{~g}$ of each sample were subjected to the analysis. The gas chromatography was equipped with a 30-m-long, 0.53-mm i.d., 1.5- $\mu \mathrm{m}$ film thickness, fused silica capillary column (HP-5, J\&W Scientific, Folsom, CA). The injection port and nitrogen-phosphorus detector temperatures were set at 230 and $300{ }^{\circ} \mathrm{C}$, respectively, with a splitless mode. Helium was used as the carrier gas with a flow rate of $5.0 \mathrm{~mL} / \mathrm{min}$. The column temperature started at $50{ }^{\circ} \mathrm{C}$, and was then programed at $5{ }^{\circ} \mathrm{C} / \mathrm{min}$ to $125^{\circ} \mathrm{C}$. The concentration of 2-acetyl-1-pyrroline in the extracts was determined using the peak area ratios of 2,6-dimethylpyridine and 2-acetyl-1-pyrroline appearing at retention times of 8.29 and $9.39 \mathrm{~min}$, respectively, and plotting them on a calibration curve, which was obtained from known concentrations of the synthetic 2-acetyl-1-pyrroline. The concentration of 2-acetyl1 -pyrroline in the rice is shown as a weight ratio per dry matter of the rice.

\subsection{Estimation of lipid peroxidation in brown rice grains}

Malondialdehyde content was measured as an additional lipid oxidation marker in brown rice grains harvested at 7 , 14, 21 and 28 days after heading, by the thiobarbituric acid method (Yong et al., 2003).

\subsection{Sensory evaluation protocol}

For sensory analysis, 2 trained panelists and 12 untrained students were selected. Two tests were conducted, one on brown rice powder and the other on milled rice. Three samples were chosen for each treatment and each sample was exposed to the panelists twice. In the first test, a portion of brown rice powder weighing exactly $20.0 \mathrm{~g}$ was placed in a $27-\mathrm{mL}$ bottle and sealed with an aluminum cap. Cooking without water was carried out in an autotherm heater (Walnut Creek, CA) with agitation for 20 minutes at $80{ }^{\circ} \mathrm{C}$. The warm cooked rice powder was placed into sniffing bottles presented to the panelists who were required to smell and say which of the samples had the most intense odor. In the second test, portions of milled rice were rinsed, and then cooked using a QLT3651 rice cooker (Taiwan Quality Group Co., Taiwan) with a rice:water ratio of 1:2. The amount of time the red light of the cooker was on was considered as the cooking time. After cooking, samples were held for $10 \mathrm{~min}$ in the cooker before testing. The aroma intensities of all rice samples were rated on a hedonic scale of 5 points: 0 for non-aromatic, 1 for subtly aromatic, 2 for clearly aromatic but not as strong as Guixiangzhan/Peizaruanxiang, 3 for aromatic and as strong as Guixiangzhan/Peizaruanxiang, and 4 for more aromatic than Guixiangzhan/Peizaruanxiang. The reference samples of Guixiangzhan and Peizaruanxiang grown without growth regulators were presented to the panelists prior to the actual test, and the two cultivars were tested in different sessions.

\subsection{Statistical analysis}

A statistical one-way analysis of variance was performed to assess differences in odor-active compound concentrations, 
Table I. Changes in relative concentrations of selected flavor molecular markers in the headspace vapor of Guixiangzhan brown rice treated at $25 \%$ panicle emergence with growth regulators. The regulator mixture consisted of paclobutrazol, proline and zinc chloride. Concentration of a compound in the headspace is expressed as internal standard equivalent (ng of 2,6-dimethylpyridine/g dry weight sample). Values in the same row for each season with different letters are significantly different $(P<0.05)$ based on Duncan's multiple range test. "Trace" means the value obtained was below the detection limit of quantification $(<0.50 \mathrm{ng} / \mathrm{g})$. ND $=$ not detected.

\begin{tabular}{|c|c|c|c|c|c|c|c|c|c|c|}
\hline \multirow[t]{3}{*}{ Compound } & \multicolumn{10}{|c|}{ Relative concentration (ng/g) } \\
\hline & \multicolumn{2}{|c|}{ Control } & \multicolumn{2}{|c|}{ Gibberellic acid } & \multicolumn{2}{|c|}{ Indole acetic acid } & \multicolumn{2}{|c|}{ Paclobutrazol } & \multicolumn{2}{|c|}{ Regulator mixture } \\
\hline & $\begin{array}{c}\text { Late } \\
\text { season }\end{array}$ & $\begin{array}{c}\text { Early } \\
\text { season }\end{array}$ & $\begin{array}{c}\text { Late } \\
\text { season }\end{array}$ & $\begin{array}{c}\text { Early } \\
\text { season }\end{array}$ & $\begin{array}{c}\text { Late } \\
\text { season }\end{array}$ & $\begin{array}{c}\text { Early } \\
\text { season }\end{array}$ & $\begin{array}{c}\text { Late } \\
\text { season }\end{array}$ & $\begin{array}{c}\text { Early } \\
\text { season }\end{array}$ & $\begin{array}{c}\text { Late } \\
\text { season }\end{array}$ & $\begin{array}{c}\text { Early } \\
\text { season }\end{array}$ \\
\hline \multicolumn{11}{|c|}{ Aliphatic alcohols } \\
\hline 1-pentanol & $12.65 \mathrm{a}$ & $12.28 \mathrm{a}$ & $2.49 \mathrm{~b}$ & $1.50 \mathrm{c}$ & $2.39 b$ & $2.13 c$ & $2.49 b$ & $4.63 b$ & $2.87 b$ & $2.10 \mathrm{c}$ \\
\hline 1-hexanol & $7.74 \mathrm{a}$ & $9.37 \mathrm{a}$ & $2.08 \mathrm{~b}$ & $4.37 b$ & $1.69 \mathrm{~b}$ & $4.78 b$ & $1.66 \mathrm{~b}$ & $0.80 \mathrm{c}$ & $1.99 \mathrm{~b}$ & $1.62 \mathrm{c}$ \\
\hline 1-heptanol & $9.69 \mathrm{a}$ & $10.57 \mathrm{a}$ & $1.63 b$ & $1.31 b$ & $0.95 b$ & $0.85 b$ & $0.67 b$ & $0.94 b$ & $0.79 b$ & $1.39 b$ \\
\hline 1-octanol & $16.39 \mathrm{a}$ & $11.36 \mathrm{a}$ & $3.48 b$ & $4.86 b$ & $3.98 b$ & $5.87 \mathrm{~b}$ & $3.42 \mathrm{~b}$ & $2.94 \mathrm{c}$ & $4.67 b$ & $4.94 b$ \\
\hline 1-nonanol & $30.70 \mathrm{a}$ & $25.23 \mathrm{a}$ & $6.60 \mathrm{~b}$ & $9.19 b$ & $4.07 \mathrm{~b}$ & $3.97 \mathrm{c}$ & $3.43 b$ & $4.19 \mathrm{c}$ & $3.01 \mathrm{~b}$ & $3.80 \mathrm{c}$ \\
\hline \multicolumn{11}{|c|}{ Aromatics } \\
\hline benzaldehyde & 7.22 & ND & ND & ND & 7.41 & ND & ND & ND & ND & ND \\
\hline \multicolumn{11}{|c|}{ Aliphatic aldehydes } \\
\hline hexanal & $6.19 \mathrm{a}$ & $10.34 \mathrm{a}$ & $1.49 \mathrm{~b}$ & $2.22 \mathrm{~b}$ & $2.09 \mathrm{~b}$ & $2.64 b$ & $2.00 \mathrm{~b}$ & $1.87 \mathrm{~b}$ & $2.22 b$ & $2.27 \mathrm{~b}$ \\
\hline (E)-2-hexenal & $8.19 \mathrm{a}$ & $8.98 \mathrm{a}$ & $2.91 \mathrm{c}$ & $5.24 b$ & $6.07 b$ & $4.55 b$ & $6.15 b$ & $4.74 b$ & $6.41 b$ & $5.76 b$ \\
\hline octanal & $4.15 \mathrm{a}$ & $6.96 \mathrm{a}$ & $0.77 \mathrm{~b}$ & $1.10 \mathrm{bc}$ & $0.69 b$ & $0.93 \mathrm{c}$ & $0.65 b$ & $1.23 \mathrm{bc}$ & $0.82 b$ & trace \\
\hline nonanal & $13.59 \mathrm{a}$ & $15.99 \mathrm{a}$ & $4.59 \mathrm{c}$ & $8.14 \mathrm{bc}$ & $14.19 \mathrm{a}$ & $6.04 \mathrm{~d}$ & $6.34 \mathrm{bc}$ & $6.99 \mathrm{~cd}$ & $8.15 b$ & $9.31 b$ \\
\hline decanal & $11.04 \mathrm{a}$ & $13.79 \mathrm{a}$ & $3.16 b$ & $1.08 \mathrm{c}$ & $3.52 b$ & $1.09 \mathrm{~b}$ & $2.68 b$ & $1.13 \mathrm{c}$ & $1.12 b$ & $1.25 \mathrm{c}$ \\
\hline \multicolumn{11}{|c|}{ N-containing compounds } \\
\hline 2-acetyl-1-pyrroline & $6.52 \mathrm{a}$ & $3.60 \mathrm{a}$ & $2.37 \mathrm{~cd}$ & $1.46 \mathrm{c}$ & $3.46 \mathrm{c}$ & $2.05 b$ & $4.05 b$ & $1.76 b c$ & $1.90 \mathrm{~d}$ & $1.63 \mathrm{bc}$ \\
\hline
\end{tabular}

odor intensity, and yield and quality parameters between control and treated samples. All analyses were carried out using SPSS 15.0 (Chicago, IL). The difference of means was resolved by means of confidence intervals using Duncan's multiple range test at $P<0.05$. A three-way analysis of variance was also conducted to estimate the effects of treatment/cultivar, season and replication on aroma compounds detected and rice odor. Season and replication were considered as random effects; therefore a compound $F$-test was used for calculating $F$ values. Data presented are an average of duplicate determinations for each sample with three samples per treatment.

\section{RESULTS AND DISCUSSION}

\subsection{Separation and identification of odor-active compounds}

In this study, 2-acetyl-1-pyrroline and lipid-derived volatile compounds were selected to elucidate the overall effect of foliar application of growth regulators at approximately $25 \%$ panicle emergence on the aroma of two aromatic rice cultivars. It should be kept in mind that our intent was not to assess the relative importance of each compound in the overall aroma of the two rices, but just to compare major compounds previously identified in rice.

In our study, static headspace coupled with gas chromatography appeared a suitable choice for the isolation of com- pounds of interest. A selection was made between two detectors, a flame ionization detector for the determination of lipid oxidation volatiles and other major volatiles, and a nitrogenphosphorus detector for 2-acetyl-1-pyrroline (Fig. 1). Overall, 12 compounds emanating from the headspace of the two rices were identified with some certainty and used in the study. They belonged to the chemical classes of alcohols (5), aromatics (1), aldehydes (5) and nitrogen-containing compounds (1).

\subsection{Influence of growth regulators on 2-acetyl-1-pyrroline content}

When changes to 2-acetyl-1-pyrroline content after foliar application of growth regulators on rice plants are considered, it can be seen that in all treated samples, the level of 2-acetyl1 -pyrroline decreased significantly $(P<0.05)$ compared with controls treated with distilled water, with a similar behavior in both cultivars (Tabs. I, II). A good correlation between the concentration of 2-acetyl-1-pyrroline, referred to as pleasant and popcorn-like in various rice samples, and sensory intensity has been established (Champagne, 2008; Maraval et al., 2008; Yang et al., 2008). Therefore, 2-acetyl-1-pyrroline has been widely used as a good indicator of aroma and flavor quality in rice.

In Guixiangzhan, control samples grown during the late season had a 2-acetyl-1-pyrroline relative concentration of 
Abundance

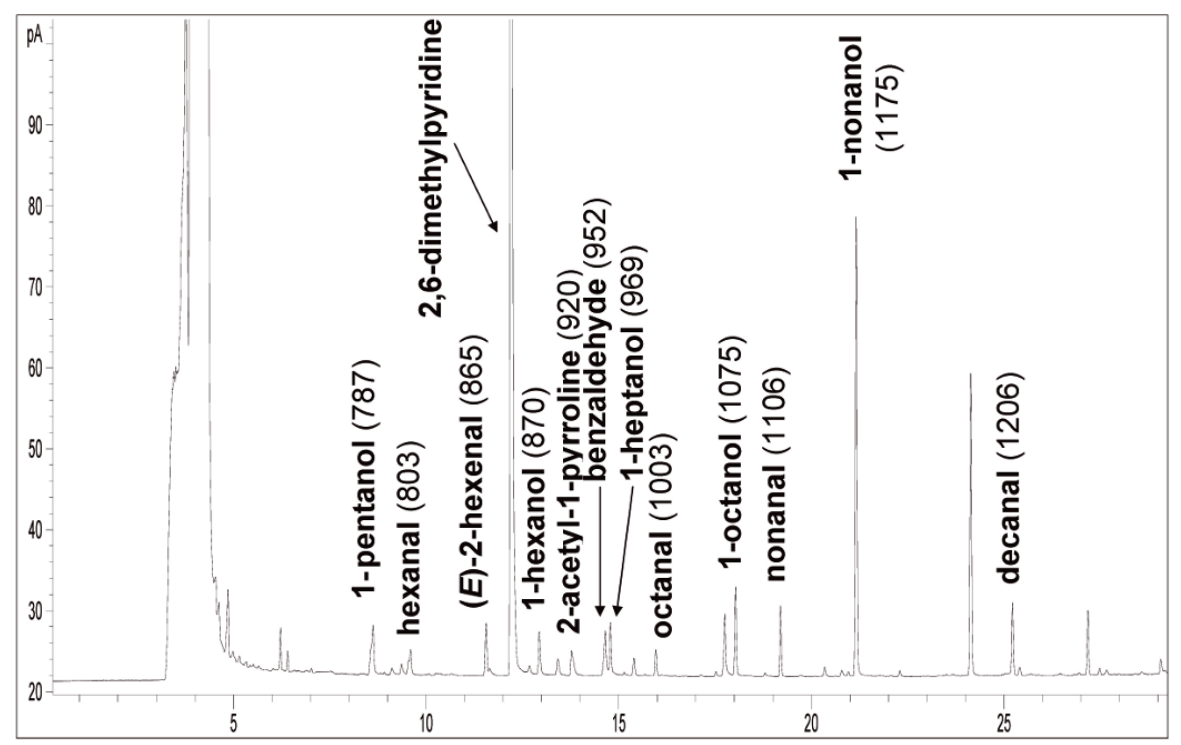

Retention time (min)

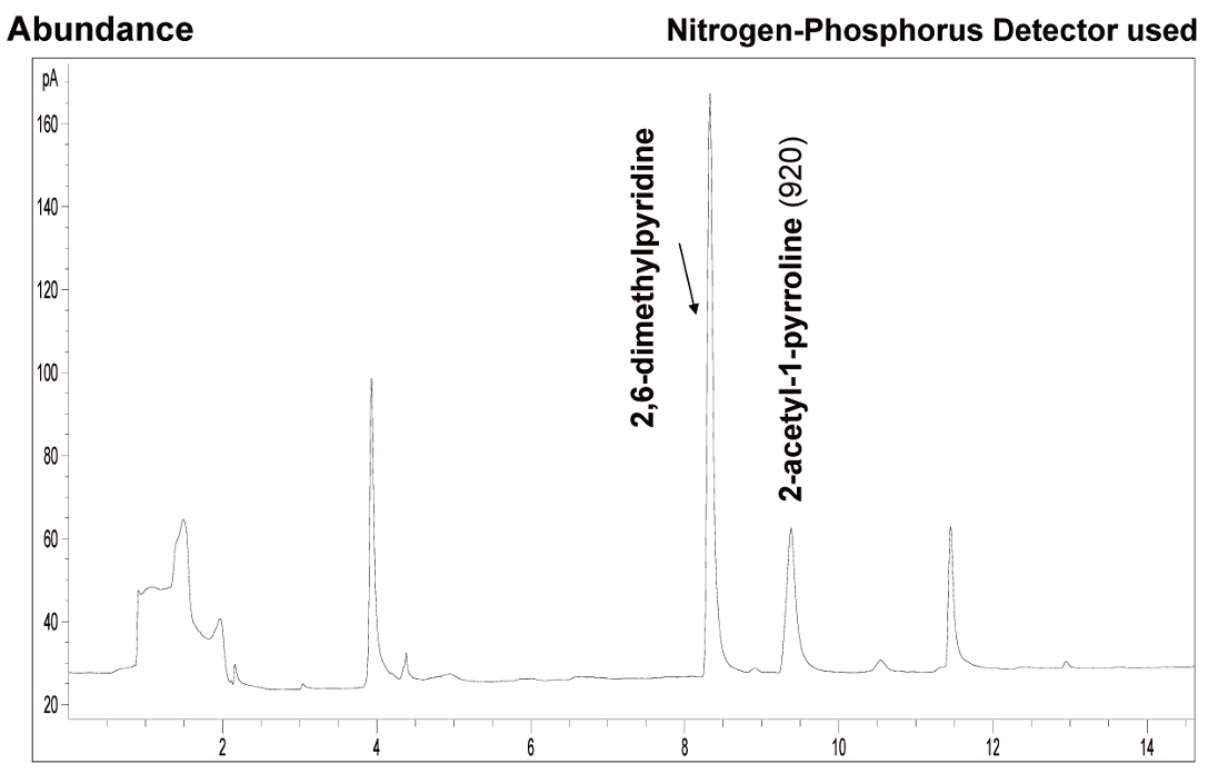

Retention time (min)

Figure 1. Typical gas chromatography/flame ionization detector and gas chromatography/nitrogen-phosphorus detector profiles of headspace volatiles in Guixiangzhan brown rice grains obtained from samples treated with distilled water at $25 \%$ panicle emergence. Compounds are followed in parenthesis by their corresponding retention indexes calculated based on a series of $n$-hydrocarbons using a HP-5MS column. 2,6-dimethylpyridine is used as an internal standard.

$6.25 \mathrm{ng} / \mathrm{g}$. 2-Acetyl-1-pyrroline in samples treated with growth regulators ranged in concentration from $1.90 \mathrm{ng} / \mathrm{g}$ for the regulator mixture to $4.05 \mathrm{ng} / \mathrm{g}$ for paclobutrazol (Tab. I). In Peizaruanxiang, gibberellic acid treatment decreased the concentration of 2-acetyl-1-pyrroline by 32\%, 3-indole acetic acid by $21 \%$, paclobutrazol by $30 \%$, and the regulator mixture by $47 \%$ compared with the control, which has a concentration of $1.71 \mathrm{ng} / \mathrm{g}$ (Tab. II). Similar trends were observed with samples grown during the early season with decreases ranging from 43 to $59 \%$ for Guixiangzhan and 35 to $56 \%$ for Peizaruanxiang. The three-way analysis of variance showed that there were significant $(P<0.05)$ cultivar and treatment effects on 2 -acetyl1 -pyrroline content. Significant $(P<0.05)$ season-by-cultivar and season-by-treatment interactions were also observed.

Quantification of 2-acetyl-1-pyrroline was performed using static headspace coupled to gas chromatography and a nitrogen-phosphorus detector, and the content in early and late harvest samples calculated from a linear calibration curve 
Table II. Changes in relative concentrations of selected flavor molecular markers in the headspace vapor of Peizaruanxiang brown rice treated at $25 \%$ panicle emergence with growth regulators. The regulator mixture consisted of paclobutrazol, proline and zinc chloride. Concentration of a compound in the headspace is expressed as internal standard equivalent (ng of 2,6-dimethylpyridine/g dry weight sample). Values in the same row with different letters for each season are significantly different $(P<0.05)$ based on Duncan's multiple range test. "Trace" means the value obtained was below the detection limit of quantification $(<0.50 \mathrm{ng} / \mathrm{g})$. ND $=$ not detected.

\begin{tabular}{|c|c|c|c|c|c|c|c|c|c|c|}
\hline \multirow[t]{3}{*}{ Compound } & \multicolumn{10}{|c|}{ Relative concentration (ng/g) } \\
\hline & \multicolumn{2}{|c|}{ Control } & \multicolumn{2}{|c|}{ Gibberellic acid } & \multicolumn{2}{|c|}{ Indole acetic acid } & \multicolumn{2}{|c|}{ Paclobutrazol } & \multicolumn{2}{|c|}{ Regulator mixture } \\
\hline & $\begin{array}{c}\text { Late } \\
\text { season }\end{array}$ & $\begin{array}{l}\text { Early } \\
\text { season }\end{array}$ & $\begin{array}{c}\text { Late } \\
\text { season }\end{array}$ & $\begin{array}{l}\text { Early } \\
\text { season }\end{array}$ & $\begin{array}{c}\text { Late } \\
\text { season }\end{array}$ & $\begin{array}{l}\text { Early } \\
\text { season }\end{array}$ & $\begin{array}{c}\text { Late } \\
\text { season }\end{array}$ & $\begin{array}{l}\text { Early } \\
\text { season }\end{array}$ & $\begin{array}{c}\text { Late } \\
\text { Late season }\end{array}$ & $\begin{array}{l}\text { Early } \\
\text { season }\end{array}$ \\
\hline \multicolumn{11}{|c|}{ Aliphatic alcohols } \\
\hline 1-pentanol & $2.83 \mathrm{ab}$ & $3.14 \mathrm{a}$ & $1.43 \mathrm{c}$ & $1.51 \mathrm{c}$ & $2.79 \mathrm{ab}$ & $2.07 \mathrm{~b}$ & $2.30 \mathrm{~b}$ & $1.75 \mathrm{bc}$ & $2.40 \mathrm{a}$ & $1.55 \mathrm{c}$ \\
\hline 1-hexanol & $2.15 \mathrm{a}$ & $3.37 \mathrm{a}$ & $1.56 \mathrm{c}$ & $1.18 \mathrm{~b}$ & $1.84 \mathrm{abc}$ & $1.21 \mathrm{~b}$ & $1.58 \mathrm{bc}$ & $1.48 \mathrm{~b}$ & $1.82 \mathrm{abc}$ & $1.30 \mathrm{~b}$ \\
\hline 1-heptanol & $0.95 \mathrm{a}$ & $1.35 \mathrm{a}$ & $0.85 \mathrm{a}$ & $1.06 \mathrm{~b}$ & $0.95 \mathrm{a}$ & $1.09 \mathrm{~b}$ & trace & $1.27 \mathrm{ab}$ & trace & $1.10 \mathrm{ab}$ \\
\hline 1-octanol & $3.47 \mathrm{a}$ & $4.09 \mathrm{a}$ & $2.52 \mathrm{~b}$ & $3.02 b$ & $3.97 \mathrm{a}$ & $3.35 b$ & $3.26 \mathrm{ab}$ & $3.07 \mathrm{~b}$ & $3.58 \mathrm{a}$ & $3.15 b$ \\
\hline 1-nonanol & $2.73 \mathrm{a}$ & $2.42 \mathrm{a}$ & $1.70 \mathrm{c}$ & trace & $2.40 \mathrm{ab}$ & $1.76 b$ & $1.82 \mathrm{bc}$ & $1.69 b$ & $1.67 \mathrm{c}$ & $1.84 \mathrm{ab}$ \\
\hline \multicolumn{11}{|c|}{ Aromatics } \\
\hline benzaldehyde & ND & ND & ND & ND & ND & ND & ND & ND & ND & ND \\
\hline \multicolumn{11}{|c|}{ Aliphatic aldehydes } \\
\hline hexanal & $5.60 \mathrm{a}$ & $6.61 \mathrm{a}$ & $1.57 \mathrm{c}$ & $2.22 \mathrm{c}$ & $2.46 b c$ & $2.34 \mathrm{bc}$ & $3.07 \mathrm{~b}$ & $2.17 \mathrm{c}$ & $2.65 b c$ & $2.97 \mathrm{~b}$ \\
\hline$(E)$-2-hexenal & $5.62 \mathrm{a}$ & $4.76 \mathrm{a}$ & $1.83 b$ & $1.74 \mathrm{bc}$ & $5.98 \mathrm{a}$ & $2.12 \mathrm{~b}$ & $5.21 \mathrm{a}$ & $1.53 \mathrm{c}$ & $6.17 \mathrm{a}$ & $2.14 b$ \\
\hline octanal & $1.07 \mathrm{a}$ & $2.20 \mathrm{a}$ & $0.68 b$ & $0.88 b$ & $0.70 \mathrm{~b}$ & $0.89 \mathrm{~b}$ & $0.64 b$ & $0.60 \mathrm{~b}$ & $0.65 b$ & $1.08 \mathrm{~b}$ \\
\hline nonanal & $11.14 \mathrm{a}$ & $12.73 \mathrm{a}$ & $4.08 \mathrm{c}$ & $5.78 b$ & $9.80 \mathrm{a}$ & $5.45 b$ & $6.76 b$ & $5.30 \mathrm{~b}$ & $4.43 b c$ & $4.54 b$ \\
\hline decanal & 0.66 & trace & trace & trace & trace & trace & trace & trace & ND & trace \\
\hline \multicolumn{11}{|c|}{ N-containing compounds } \\
\hline 2-acetyl-1-pyrroline & $1.71 \mathrm{a}$ & $1.15 \mathrm{a}$ & $1.17 \mathrm{bc}$ & $0.75 b$ & $1.36 \mathrm{~b}$ & $0.74 b$ & $1.20 \mathrm{~b}$ & $0.51 \mathrm{~b}$ & $0.90 \mathrm{c}$ & $0.59 \mathrm{~b}$ \\
\hline
\end{tabular}

plotted with known amounts of synthetic 2-acetyl-1-pyrroline (Fig. 2). The findings were consistent with the analysis performed earlier using a flame ionization detector, where gibberellic acid, 3-indole acetic acid, paclobutrazol and the regulator mixture were shown to adversely influence 2-acetyl1-pyrroline content in both the brown and the milled rice. When averaged over treatments, it seemed that gibberellic acid, paclobutrazol and the regulator mixture produced the lowest mean 2-acetyl-1-pyrroline, $1.95,1.90$ and $1.89 \mu \mathrm{g} / \mathrm{g}$ in Guixiangzhan, respectively, and $0.35,0.34$ and $0.31 \mu \mathrm{g} / \mathrm{g}$ in Peizaruanxiang brown grains from the late season (Fig. 2). Therefore, samples treated with growth regulators are much lower in 2-acetyl-1-pyrroline, the principal rice aroma, compared with the control.

\subsection{Influence of growth regulators on lipid-derived volatiles}

Considering the changes that occurred in lipid-derived rice volatiles after foliar application of growth regulators on rice plants, it was observed that there was generally a significant $(P<0.05)$ decrease in the levels of most of the aldehydes and the alcohols, as was the case with 2-acetyl-1-pyrroline (Tabs. I, II). Recent studies have shown that aldehydes make up over $90 \%$ of all the odor-active compounds in rice (Maraval et al., 2008; Yang et al., 2008). In concentration, nonanal, de- scribed as citrus, floral and fruity (Buttery et al., 1988), was the most significant aldehyde present in the two rices, comprising $5.99 \mathrm{ng} / \mathrm{g}$ in Guixiangzhan and $12.73 \mathrm{ng} / \mathrm{g}$ in Peizaruanxiang maintained as control during the early season, and $13.59 \mathrm{ng} / \mathrm{g}$ and $11.14 \mathrm{ng} / \mathrm{g}$ during the late season, respectively. Its concentration was highest throughout the study relative to hexanal; it may, thus, have a great impact on the global aroma of the two rice cultivars. Hexanal is considered one of the most potent odorants in rice after 2-acetyl-1-pyrroline (Suzuki et al., 1999; Lam and Proctor, 2003). Hexanal contributes rancid, unpleasant notes on high dilution, but exhibits green, grass-like odors at low concentrations (Widjaja et al., 1996). Hexanal was found to have the highest contribution to milled rice odor during early storage contrary to octanal, which contributes more during long-term storage with a slightly fruity and citruslike odor (Lam and Proctor, 2003). The relative concentrations of hexanal and decanal changed by a larger factor relative to those of the other aldehydes, with decreases of 5.0 to 12.8 times in Guixiangzhan and 2.1 to 3.6 times in Peizaruanxiang. The aldehydes underwent these changes after foliar application of all growth regulators, but they were greater for samples treated with gibberellic acid during the late season. This was generally the trend of change observed for the two types of rice. An exception to this trend is $(E)$-2-hexenal, described as apple and green, which decreased in concentration in Guixiangzhan and Peizaruanxiang grown during the early season, but in Peizaruanxiang grown during the late season 

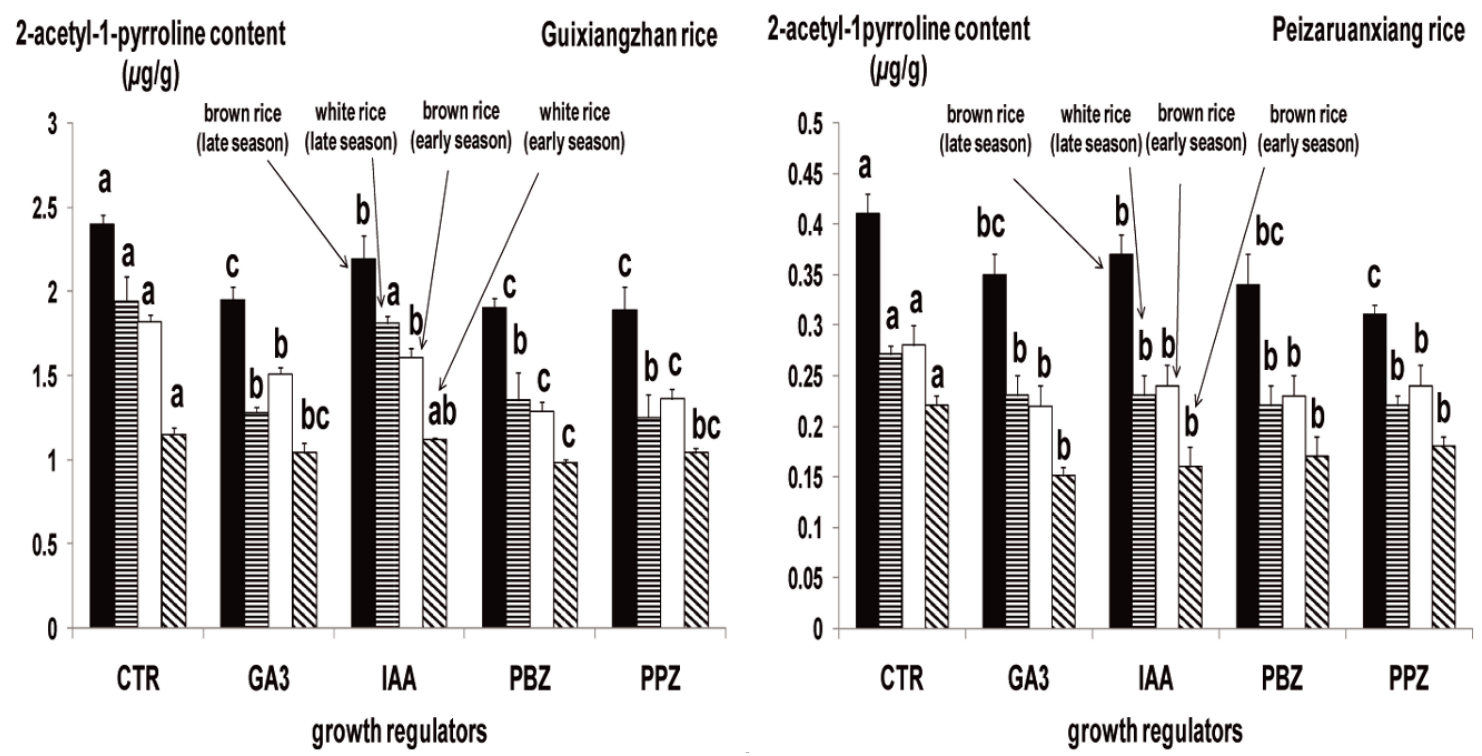

Figure 2. Comparison of 2-acetyl-1-pyrroline contents in Guixiangzhan and Peizaruanxiang rice grains after foliar application of growth regulators at $25 \%$ panicle emergence: control treated with distilled water (CTR), gibberellic acid (GA3), 3-indole acetic acid (IAA), paclobutrazol (PBZ), and a regulator mixture consisting of paclobutrazol, proline and zinc chloride (PPZ). The amount of 2-acetyl-1-pyrroline in rice samples is calculated from a calibration curve constructed using various concentrations of synthetic 2-acetyl-1-pyrroline against 2,6-dimethylpyridine used as an internal standard. Vertical bars with different letters above are significantly different $(P<0.05$, Duncan's multiple range test $)$. Capped bars represent the standard deviations.

remained constant $(P<0.05)$ after treatments with 3 -indole acetic acid (5.98 ng/g), paclobutrazol $(5.21 \mathrm{ng} / \mathrm{g})$ and the regulator mixture $(6.17 \mathrm{ng} / \mathrm{g})$ (Tab. II).

The most critical odorant among all the lipid-derived alcohols is 1-hexanol, which has more pleasant aroma descriptors such as vegetal, herbaceous and green. A clear discrimination between aromatic and non-aromatic rice cultivars was shown for this component by three papers (Petrov et al., 1996; Maraval et al., 2008; Yang et al., 2008), with 1-hexanol concentration significantly higher for aromatic rice samples. In the three studies, 1-pentanol, described as plastic, fusel and oil-like, was also identified as a discriminant and occurred in high concentration in non-aromatic rices. 1-pentanol is also one of the three major volatile components during normal lipoxygenase-3 rice storage (Suzuki et al., 1999). Consequently, the decrease in the level of volatile alcohols after foliar application of growth regulators will, hence, have a significant impact on the global aroma of rice.

Lipid-derived volatiles are thought to be produced mainly via lipid oxidation and decomposition (Lam and Proctor, 2003). More evidence of inhibition of lipid oxidation in our study is the decrease in malondialdehyde level, a non-volatile product of lipid peroxidation. Changes in malondialdehyde content with time for both the control and treated samples in the two rices grown during the late season were plotted as shown in Figure 3. Malondialdehyde was at a greater concentration in control samples treated with distilled water than samples treated with growth regulators for any harvesting time, with a similar background level for the two rices. It may be postulated that the other lipid-derived odor-active volatiles often cited in rice, such as $(E)$-2-octenal, 2-pentylfuran and $(E, E)$-2,4-decadienal also decreased in concentration due to foliar application of growth regulators.

Most of the oxidation products discussed so far have been tagged as likely causing rancid and stale flavor, and are reported to increase in concentration over time (Lam and Proctor, 2003; Wongpornchai et al., 2004). In our study (Tabs. I, II), and with the exception of 1-octanol, 1-nonanol and benzaldehyde in Guixiangzhan, and 1-nonanol, $(E)-2$ hexenal and decanal in Peizaruanxiang, all volatiles appeared to increase in concentration with storage duration in control samples, which was not the case in samples treated with growth regulators, where most lipid-derived volatiles were substantially lower in abundance or remained at relatively unchanged levels. This constitutes an interesting result and provides evidence for the ability of growth regulators to reduce off-flavor development in rice grain during storage, probably by inducing various enzymatic actions and preventing lipid hydrolysis, leading to decreases in volatile compounds, or their conversion into non-volatile compounds. The results obtained over the two growing seasons also indicate that some growth regulators could have a selective effect on the metabolism of volatile compounds like gibberellic acid on 1-hexanol, 1-octanol, 1-nonanol, $(E)$-2-hexenal and nonanal, which increased in concentration over time.

\subsection{Influence of growth regulators on aromatic compounds}

Benzaldehyde, with an almond-like odor, is one of the nine volatiles identified by Petrov et al. (1996) to discriminate 

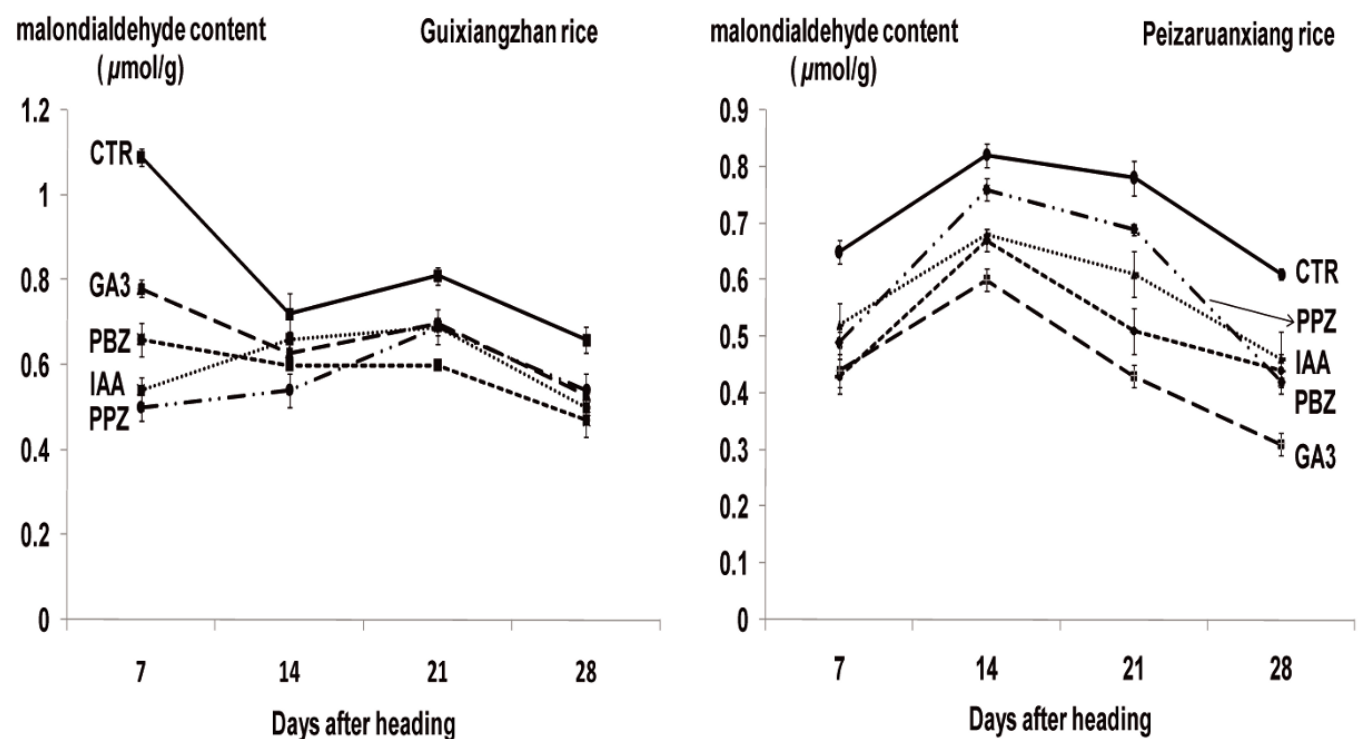

Figure 3. Evolution of malondialdehyde level during the late season in Guixiangzhan and Peizaruanxiang brown rice after foliar application of growth regulators at $25 \%$ panicle emergence: control treated with distilled water (CTR), gibberellic acid (GA3), 3-indole acetic acid (IAA), paclobutrazol (PBZ), and a regulator mixture consisting of paclobutrazol, proline and zinc chloride (PPZ). All points for each day are significantly different (Duncan's multiple range test at $P<0.05$ ) from the control. Capped vertical lines represent the standard deviations.

aromatic and non-aromatic rices. In our study, it was selected to study the effect of foliar application of growth regulators on aromatic volatile compounds in rice, and was detected only in Guixiangzhan samples grown during the late season and treated with distilled water $(7.22 \mathrm{ng} / \mathrm{g})$, and 3 -indole acetic acid $(7.41 \mathrm{ng} / \mathrm{g}$ ) (Tab. I). Therefore, treatments with growth regulators resulted in reduced benzaldehyde content.

\subsection{Influence of growth regulators on cooked rice odor}

Growing Guixiangzhan and Peizaruanxiang rice cultivars with growth regulators decreased the aroma content and changed the sensory properties to a level that could be easily detected by taste panel evaluation of brown rice powder cooked without addition of water. Similarly, in cooked milled rice, samples treated with distilled water possessed a strong characteristic aroma, which differed greatly from the odor of samples treated with growth regulators. Only a few sensory panelists, however, were able to detect a significant difference in rice odor due to treatment of Guixiangzhan with 3-indole acetic acid during the early season. Panelists gave scores from 3.11 to 3.87 for control samples and from 2.10 to 2.94 for samples treated with growth regulators (Tab. III).

As shown by the calculated $F$ values, there were no significant $(P<0.05)$ season effects on rice odor. Seasonby-cultivar and season-by-treatment interactions were, however, significant. Key thermally induced odorants in rice have also been assigned and include 2-methoxy-4-vinyphenol (spicy), 4-vinylguaiacol and 4-vinylphenol (phenolic, medicinal) (Maraval et al., 2008; Yang et al., 2008). These results indicate a decrease in their concentrations. Therefore, rice grown
Table III. Decrease in rice odor intensity after foliar application of growth regulators at $25 \%$ panicle emergence. The regulator mixture consisted of paclobutrazol, proline and zinc chloride. Means in the same column (for each rice cultivar) with different letters are significantly different $(P<0.05)$ according to Duncan's multiple range test.

\begin{tabular}{lcccc}
\hline Treatment & \multicolumn{2}{c}{ Guixiangzhan rice } & \multicolumn{2}{c}{ Peizaruanxiang rice } \\
\cline { 2 - 5 } & $\begin{array}{c}\text { Late } \\
\text { season }\end{array}$ & $\begin{array}{c}\text { Early } \\
\text { season }\end{array}$ & $\begin{array}{c}\text { Late } \\
\text { season }\end{array}$ & $\begin{array}{c}\text { Early } \\
\text { season }\end{array}$ \\
\hline Control & $3.87 \mathrm{a}$ & $3.20 \mathrm{a}$ & $3.11 \mathrm{a}$ & $3.15 \mathrm{a}$ \\
Gibberellic acid & $2.31 \mathrm{c}$ & $2.71 \mathrm{~b}$ & $2.20 \mathrm{~b}$ & $2.56 \mathrm{~b}$ \\
Indole acetic acid & $2.91 \mathrm{~b}$ & $2.94 \mathrm{ab}$ & $2.10 \mathrm{~b}$ & $2.54 \mathrm{~b}$ \\
Paclobutrazol & $2.72 \mathrm{bc}$ & $2.71 \mathrm{~b}$ & $2.76 \mathrm{~b}$ & $2.40 \mathrm{~b}$ \\
Regulator mixture & $3.04 \mathrm{~b}$ & $2.83 \mathrm{~b}$ & $2.23 \mathrm{~b}$ & $2.52 \mathrm{~b}$ \\
\hline
\end{tabular}

with growth regulators is expected to have significant decrease in flavor that may negatively affect consumer acceptance.

\subsection{Beneficial role of growth regulators}

In a general sense, growth regulators are transported from one part of the rice plant to another, where they elicit a specific response. One such response is the role that gibberellic acid, paclobutrazol and 3-indole acetic acid play in the alleviation of adverse effects of various stresses. Coincidentally, with high salinity $(\mathrm{NaCl})$ during our study, exposure to the four treatments resulted in a reversal of shoot- and leaf-related responses to salt stress (data not shown). More detailed insights into the beneficial effect of growth regulators can be obtained when stress tolerance is considered together with yield 
Table IV. Improvement in some yield and quality attributes of Guixiangzhan and Peizaruanxiang rice cultivars after foliar application of growth regulators at 25\% panicle emergence: control treated with distilled water (CTR), gibberellic acid (GA3), 3-indole acetic acid (IAA), paclobutrazol (PBZ), and a regulator mixture consisting of paclobutrazol, proline and zinc chloride (PPZ). Means in the same column (for each rice cultivar) with different letters are significantly different $(P<0.05)$ according to Duncan's multiple range test.

\begin{tabular}{|c|c|c|c|c|c|c|c|c|c|c|c|c|}
\hline \multirow[t]{2}{*}{ Treatment } & \multicolumn{2}{|c|}{$\begin{array}{l}\text { Grain yield } \\
(\mathrm{t} / \mathrm{ha})\end{array}$} & \multicolumn{2}{|c|}{$\begin{array}{l}\text { Grain weight } \\
(\mathrm{g} / 1000)\end{array}$} & \multicolumn{2}{|c|}{$\begin{array}{c}\text { Head rice yield } \\
(\%)\end{array}$} & \multicolumn{2}{|c|}{$\begin{array}{c}\text { Grain vitreosity } \\
(\%)\end{array}$} & \multicolumn{2}{|c|}{$\begin{array}{c}\text { Amylose content } \\
(\%)\end{array}$} & \multicolumn{2}{|c|}{$\begin{array}{c}\text { Protein content } \\
(\%)\end{array}$} \\
\hline & $\begin{array}{c}\text { Late } \\
\text { season }\end{array}$ & $\begin{array}{c}\text { Early } \\
\text { season }\end{array}$ & $\begin{array}{c}\text { Late } \\
\text { season }\end{array}$ & $\begin{array}{l}\text { Early } \\
\text { season }\end{array}$ & $\begin{array}{c}\text { Late } \\
\text { season }\end{array}$ & $\begin{array}{c}\text { Early } \\
\text { season }\end{array}$ & $\begin{array}{c}\text { Late } \\
\text { season }\end{array}$ & $\begin{array}{c}\text { Early } \\
\text { season }\end{array}$ & $\begin{array}{c}\text { Late } \\
\text { season }\end{array}$ & $\begin{array}{c}\text { Early } \\
\text { season }\end{array}$ & $\begin{array}{c}\text { Late } \\
\text { season }\end{array}$ & $\begin{array}{r}\text { Early } \\
\text { season }\end{array}$ \\
\hline \multicolumn{13}{|c|}{ Guixiangzhan rice } \\
\hline CTR & $5.09 \mathrm{~b}$ & $4.72 b$ & $25.92 \mathrm{ab}$ & $25.11 \mathrm{a}$ & $65.15 a$ & $48.35 c$ & $89.33 \mathrm{ab}$ & $88.33 b$ & $19.51 \mathrm{ab}$ & $17.60 \mathrm{ab}$ & $8.01 \mathrm{~b}$ & $7.90 \mathrm{~b}$ \\
\hline GA3 & $6.41 \mathrm{a}$ & $5.71 \mathrm{a}$ & $26.21 \mathrm{ab}$ & $26.42 \mathrm{a}$ & $63.28 b$ & $48.46 \mathrm{bc}$ & $86.33 b$ & $86.33 c$ & $18.89 \mathrm{~b}$ & $16.13 b$ & $7.02 \mathrm{c}$ & $7.71 b$ \\
\hline PBZ & $5.55 \mathrm{ab}$ & $4.95 b$ & $25.61 b$ & $26.25 \mathrm{a}$ & $64.44 \mathrm{ab}$ & $48.84 \mathrm{ab}$ & $87.67 \mathrm{ab}$ & $88.00 \mathrm{bc}$ & $20.62 a$ & $16.60 \mathrm{ab}$ & $8.07 \mathrm{~b}$ & $8.04 \mathrm{ab}$ \\
\hline PPZ & $5.47 \mathrm{~b}$ & $4.97 b$ & $26.05 \mathrm{ab}$ & $26.10 \mathrm{a}$ & $64.72 \mathrm{ab}$ & $48.78 \mathrm{ab}$ & $87.33 b$ & $88.33 b$ & $19.64 a b$ & $16.17 \mathrm{~b}$ & $8.00 \mathrm{~b}$ & $7.78 b$ \\
\hline \multicolumn{13}{|c|}{ Peizaruanxiang rice } \\
\hline CTR & $6.44 b$ & $5.18 \mathrm{c}$ & $21.70 \mathrm{~b}$ & $21.14 b c$ & $65.72 \mathrm{ab}$ & $56.17 \mathrm{~b}$ & $80.33 b$ & $78.33 b$ & $28.20 \mathrm{a}$ & $28.10 \mathrm{a}$ & $8.09 \mathrm{bc}$ & $8.11 \mathrm{~b}$ \\
\hline GA3 & $7.60 \mathrm{a}$ & $6.44 \mathrm{a}$ & $21.09 \mathrm{c}$ & $20.22 \mathrm{c}$ & $63.19 \mathrm{c}$ & $55.74 b$ & $81.33 b$ & $80.00 \mathrm{~b}$ & $28.27 \mathrm{a}$ & $26.13 b$ & $7.77 \mathrm{c}$ & $7.39 \mathrm{c}$ \\
\hline
\end{tabular}

and quality parameters. It can be seen from Table IV that for most of the yield and quality parameters measured, there were one or more treatments with growth regulators under which an improvement was found. The highest grain yield was obtained with gibberellic acid during both growing seasons, 6.41 and 5.71, 7.60 and 6.44 t/ha in Guixiangzhan and Peizaruanxiang, respectively. Paclobutrazol seemingly produced the highest head rice rate $(65.96 \%)$ and grain vitreosity $(85.67 \%)$ in Peizaruanxiang, while treatment with 3 -indole acetic acid was beneficial to 1000 -grain weight $(27.23 ; 22.12 \mathrm{~g})$, head rice yield $(65.48 ; 66.34 \%)$, grain vitreosity $(90.67 ; 83.00 \%)$, amylose content $(20.38 ; 25.76 \%)$ and protein content $(8.68$; $9.06 \%$ ).

Leaf-applied growth regulators can enter the leaf either by penetration of the cuticle or via the stomatal pathway, and affect rice growth by way of several mechanisms. Paclobutrazol, for example, has been widely used with marked success to reduce plant height and increase chlorophyll content in aromatic rice plants. Paclobutrazol is translocated primarily apo-plastically through the xylem to its site of action where it decreases the rate of cell division and elongation by the inhibition of ent-kaurene oxidase, which catalyzes the sequential oxidations from ent-kaurene to ent-kaurenoic acid in the early sequence of gibberellic acid biosynthesis (Yim et al., 1997). Gibberellic acid is associated with the stimulation of the formation of hydrolytic enzymes in germinating cereal grain and the induction of carbohydrate translocation (Mander, 2003). The most significant physiological effect of exogenous gibberellic acid on rice plants is to break dwarfism and stimulate the elongation of leaves and stems. The pathways of formation of volatile aroma compounds in the rice plant are, therefore, very important to understand the mechanisms of action of growth regulators in rice.
Although L-proline was identified as the principal precursor of 2-acetyl-1-pyrroline in rice (Yoshihashi et al., 2002), the biochemical pathways of 2-acetyl-1-pyrroline synthesis are presently not well elucidated (Bourgis et al., 2008). Fragrance in rice is reported to be due to an eight-base pair deletion in exon 7 of a gene on chromosome 8 encoding a putative betaine aldehyde dehydrogenase 2 . Chen et al. (2008) suggested that the functional betaine aldehyde dehydrogenase 2 inhibits 2-acetyl-1-pyrroline biosynthesis in non-fragrant rice by converting 4-aminobutyraldehyde into 4aminobutyric acid, while the non-functional enzyme results in 4-aminobutyraldehyde accumulation, leading to the formation of 2-acetyl-1-pyrroline in fragrant rice. Bradbury et al. (2008a) instead suggested $\gamma$-aminobutyraldehyde as the effective substrate for betaine aldehyde dehydrogenase 2. On the contrary, Huang et al. (2008) did not propose any direct role for betaine aldehyde dehydrogenase 2 . Their work led to the conclusion that $\Delta^{1}$-pyrroline-5-carboxylate, usually the immediate precursor of proline synthesized from glutamate, reacts directly with methylglyoxal to form 2-acetyl-1-pyrroline. Although the pathways proposed may exist, decreases in the levels of volatile compounds in rice found after treatment with growth regulators can mostly be explained by side activities on enzymes involved in the biosynthesis of 2-acetyl-1-pyrroline and other volatile compounds and the alteration of the mechanisms involved in their transport. In the case of betaine aldehyde dehydrogenase 2-dependent 2-acetyl-1-pyrroline synthesis, decreases in 2-acetyl-1-pyrroline accumulation in response to growth regulators could be attributed to an activation of betaine aldehyde dehydrogenase 2 . In the second case, foliar application of growth regulators would have reduced the activity of enzymes involved in proline biosynthesis from glutamine and which include glutamine synthetase, glutamate 
synthase and $\Delta^{1}$-pyrroline-5-carboxylate synthetase. Other enzymatic activities cannot, however, be excluded. This hypothesis should be tested in the light of recent findings which showed that at least one other mutation drives the accumulation of 2-acetyl-1-pyrroline (Bourgis et al., 2008; Fitzgerald et al., 2008).

The major deteriorating mechanism occurring in rice being lipid oxidation and decomposition, the low level observed for lipid-derived volatiles can be explained by the inhibition of lipooxygenase and lipase activities and hence a reduction of the rate of oxidation of unsaturated fatty acids such as oleic and linoleic acids (Suzuki et al., 1999). The same comment might hold true for benzaldehyde, which is reported to originate from oxidation reactions of cinnamic acid or phenylacetaldehyde.

In any case, the possibility of other mechanisms operating in parallel should also be considered. Interaction of aroma compounds with other compounds such as starch matrices, lipids and proteins, may increase or decrease aroma retention even during cooking (Champagne, 2008). Storage tests indicated that 2-acetyl-1-pyrroline can exist as a complex within the hydrophobic region of crystalline starch (Yoshihashi et al., 2002). Growth regulators can affect the matrix composition and the migration process of aroma molecules which, in turn, will affect the flavor perceived. It has also been demonstrated that the application of exogenous auxins such as 3-indole acetic acid alters the gland formation process, the number of glands produced and their integrity in many plants by inhibiting the formation of trichomes, which would affect the biosynthesis of volatile compounds and their secretion from glands and mesophyll cells into intercellular spaces (Sudria et al., 2001).

We would have expected a positive effect of proline application on the aroma quality of the two fragrant rice cultivars because of its possible involvement in the biosynthesis of 2-acetyl-1-pyrroline (Yoshihashi et al., 2002). This was, however, not the case in our work. This was probably because proline was applied along with zinc chloride and paclobutrazol, the latter being predominant in its activity. Another explanation is that it is a biosynthetic pathway in aromatic rice grains which leads to the formation of 2-acetyl-1-pyrroline from proline and not the level of free proline.

\section{CONCLUSION}

As evidenced by this study, foliar treatment of aromatic rice plants at panicle emergence with growth regulators at optimum concentrations, although improving grain yield and quality, resulted in reduced aroma content and flavor. In a confirmatory sensory evaluation, rice flavor was most intense in cooked rice from the control plots than samples treated with gibberellic acid, paclobutrazol and 3-indole acetic acid. Although the type of action of growth regulators can be highly variable depending on cultivar, concentration, and time and mode of application, we recommend that normal agronomic practices without application of regulators are adhered to. If growth regulators are to be used for purposes such as improved yield and quality, and survival under stress conditions, then the aroma quality needs to be carefully monitored.

\section{REFERENCES}

Bourgis F., Guyot R., Gherbi H., Tailliez E., Amabile I., Salse J., Lorieux M., Delseny M., Ghesquière A. (2008) Characterization of the major fragrance gene from an aromatic japonica rice and analysis of its diversity in Asian cultivated rice, Theor. Appl. Genet. 117, $353-368$.

Bradbury L.M.T., Gillies S.A., Brushett D.J., Waters D.L.E., Henry R.J. (2008a). Inactivation of an aminoaldehyde dehydrogenase is responsible for fragrance in rice, Plant Mol. Biol. 68, 439-449.

Bradbury M.L.T., Henry R.J., Waters D.L.E. (2008b) Flavor development in rice, in: Havkin-Frenkel D., Belanger F.C. (Eds.), Biotechnology in flavor production. Blackwell Publishing Ltd, Oxon, UK, pp. 130-146.

Buttery R.G., Turnbaugh J.G., Ling L.C. (1988) Contribution of volatiles to rice aroma, J. Agric. Food Chem. 36, 1006-1009.

Champagne E.T. (2008) Rice aroma and flavor: a literature review, Cereal Chem. 85, 445-454.

Chen S., Yang Y., Shi W., Ji Q., He F., Zhang Z., Cheng Z., Liu X., Xu M. (2008) Badh2, encoding betaine aldehyde dehydrogenase, inhibits the biosynthesis of 2-acetyl-1-pyrroline, a major component in rice fragrance, Plant Cell 20, 1850-1861.

Fitzgerald M.A., Hamilton N.R.S., Calingacion M.N., Verhoeven H.A., Butardo V.M. (2008) Is there a second fragrance gene in rice? Plant Biotechnol. J. 6, 416-423.

Goufo P., Duan M., Wongpornchai S., Tang X. (2010) Some factors affecting concentration of the aroma compound 2-acetyl-1-pyrroline in two fragrant rice cultivars grown in South China, Front. Agric. China 4, 1-9.

Huang T.C., Teng C.S., Chang J.L., Chuang H.S., Ho C.T., Wu M.L. (2008) Biosynthetic mechanism of 2-acetyl-1-pyrroline and its relationship with pyrroline-5-carboxylic acid and methylglyoxal in aromatic rice callus, J. Agric. Food Chem. 56, 7399-7404.

Juliano B.O., Villareal C.P. (1993) Grain quality evaluation of world rices, International Rice Research Institute, Manila, Philippines.

Lam H.S., Proctor A. (2003) Milled rice oxidation volatiles and odor development, J. Food Sci. 68, 2676-2681.

Lançon J., Wery J., Rapidel B., Angokaye M., Gérardeaux E., Gaborel C., Ballo D., Fadegnon B. (2007) An improved methodology for integrated crop management systems, Agron. Sustain. Dev. 27, $101-110$.

Loutfi K., Chlyah H. (1998) Vegetative multiplication of date palms from in vitro cultured inflorescences: effect of some growth regulator combinations and organogenetic potential of various cultivars, Agron. Sustain. Dev. 18, 573-580.

Mander L.N. (2003) Twenty years of gibberellins research, Nat. Prod. Rep. 20, 49-69.

Maraval I., Mestres C., Pernin K., Ribeyre F., Boulanger R., Guichard E., Gunata Z. (2008) Odor-active compounds in cooked rice cultivars from Camargue (France) analyzed by GC-O and GC-MS, J. Agric. Food Chem. 56, 5291-5298.

Petrov M., Danzart M., Giampaoli P., Faure J., Richard H. (1996) Rice aroma analysis: discrimination between a scented and non-scented rice, Sci. Aliments 16, 347-360. 
Sawan Z.M., Sakr R.A. (1998) Effect of 1-naphthalene acetic acid concentrations and the number of applications on the yield components, yield and fibre properties of the Egyptian cotton (Gossypium barbadehse L.), Agron. Sustain. Dev. 18, 275-283.

Sriseadka T., Wongpornchai S., Kitsawatpaiboon P. (2006) Rapid method for quantitative analysis of the aroma impact compound, 2-acetyl1-pyrroline, in fragrant rice using automated headspace gas chromatography, J. Agric. Food Chem. 54, 8183-8189.

Sudria C., Palazon J., Cusido R., Bonfill M., Pinol M.T., Morales C. (2001) Effect of benzyladenine and indolebutyric acid on ultrastructure, glands formation, and essential oil accumulation in Lavandula dentata plantlets, Biol. Plant. 44, 1-6.

Suzuki Y., Ise K., Li C., Honda I., Iwai Y., Matsukura U. (1999) Volatile components in stored rice (Oryza sativa L.) varieties with and without lipoxygenase-3 in seeds, J. Agric. Food Chem. 47, 1119-1124.

Widjaja R., Craske J.D., Wootton M. (1996) Comparative studies on volatile components of non-fragrant and fragrant rices, J. Sci. Food Agric. 70, 151-161.
Wongpornchai S., Dumri K., Jongkaewwattana S., Siri B. (2004) Effects of drying methods and storage time on the aroma and milling quality of rice (Oryza sativa L.) cv. Khao Dawk Mali 105, Food Chem. $87,407-414$

Yang D.S., Shewfelt R.L., Lee K.S., Kays S.J. (2008) Comparison of odor-active compounds from six distinctly different rice flavor types, J. Agric. Food Chem. 56, 2780-2787.

Yim K.O., Kwon Y.W., Bayer D.E. (1997) Growth responses and allocation of assimilates of rice seedlings by paclobutrazol and gibberellin treatment, J. Plant Growth Regul. 16, 35-41.

Yong I.K., Ji S.S., Nilda R.B., Tay E.H., Oksoo H., Baik H.C., Sunyo J., Ja O.G. (2003) Antioxidative enzymes offer protection from chilling damage in rice plants, Crop Sci. 43, 2109-2117.

Yoshihashi T.N., Nguyen T.T.H., Inatomi H. (2002) Precursors of $2-$ acetyl-1-pyrroline, a potent flavor compound of an aromatic rice variety, J. Agric. Food Chem. 50, 2001-2004. 